\title{
DBD Plasma Influence on the Adhesion of Paints on Polymeric Substrates
}

\author{
Jindřich Matoušek, ${ }^{1,{ }^{*}}$ Pavlína Hájková ${ }^{2,3}$ and Jakub Perner ${ }^{1}$ \\ ${ }^{1}$ University of J.E.Purkyně, Faculty of Science, Department of Physics, České mládeže 8, \\ 40096 Ústí nad Labem, Czech Republic. \\ ${ }^{2}$ Unipetrol Centre for Research and Education, Revoluční 84, 40001 Ústí nad Labem, Czech Republic \\ ${ }^{3}$ Technical University of Liberec, Department of Material Science, Studentská 2, 46117 Liberec, Czech Republic \\ *Corresponding author: E-mail: jindrich.matousek@ujep.cz
}

Received: 04-04-2019

\begin{abstract}
The, polyethylene (PE), polypropylene (PP) and polycarbonate (PC) flat substrates were treated by the DBD plasma in air for $1 \mathrm{~s}, 2 \mathrm{~s}$ and $3 \mathrm{~s}$. The adhesion of two types of paints (water based and solvent based) was studied by the pull-off test. The other methods were utilized to gain the information about the surface of the samples. The measurement of contact angle of water and Arcotest (commercial test using set of fluids with defined surface tension) and the XPS technique were used to obtain the chemical composition of the sample surface. The pull-off test confirmed increased adhesion of both types of paints, which is related to oxygen content confirmed by XPS. The aged (60 days) samples keep their enhanced properties although some return to initial state was observed.
\end{abstract}

Keywords: DBD plasma; polymer; adhesion

\section{Introduction}

The polymers are known for their low surface energy which then causes low adhesion of various paints to the polymers. These days the polymers production is one of the largest industrial branches and all manufacturers have to deal with the paint adhesion, which can be increased by various ways. Use of chemicals, UV light or flame treatment was described. ${ }^{1,2}$ The use of aggressive chemicals is environmentally unfriendly, although effective. Another possibility is the plasma treatment. Either plasma polymer coating can be created (plasma deposition from gas phase) or plasma itself can be used to create functional groups on the polymeric surface. Many research groups studied the plasma treatment of polymers. ${ }^{3-9}$ The plasma treatment methods usually need to achieve low pressure with the exception of the atmospheric pressure plasma treatment. This is one of the drawbacks of plasma technologies - high initial cost of the equipment. To overcome the need of vacuum equipment installation, the atmospheric plasma can also be used. Although the atmospheric discharges have own specific difficulties - e.g. expensive $\mathrm{He}$ is often needed for better discharge stabilisation - it is possible to find ap- plications, where the helium does not need to be used. ${ }^{10,11}$ This is the case of dielectric barrier discharge (DBD) that can be used for treatment of polymers and for the adhesion improvement. In this study we used DBD discharge for plasma treatment of various polymers to enhance the adhesion of two classes of paints (water based and solvent based) and we characterized the surface chemistry and adhesion by several methods mentioned in following sections.

\section{Materials and Methods}

\section{1. Substrates}

Three different polymers were used. The oxygen containing groups can influence the surface energy and therefore polymers with and without oxygen were selected. Two of them were polyolefins: polyethylene (PE) and polypropylene (PP), the third one was oxygen containing polymer with more complex structure - polycarbonate (PC). These polymers were selected also because they are ones of the most often used polymers in the industry. The samples were supplied by Goodfellow: (UHMW PE, PP, PC sheets) and were $3 \mathrm{~mm}$ thick flat pieces that were cut to the same 
size $(6 \mathrm{~cm} \times 14 \mathrm{~cm})$, cleaned by isopropyl alcohol and let dry. The structure of $\mathrm{PE}$ and $\mathrm{PP}$ is considered to be known well. The structural formula of PC is given in Fig. 1.<smiles>CC(C)(C)CCC(C)(C)C</smiles><smiles>CC(C(C)(C)C)C(C)(C)C</smiles>

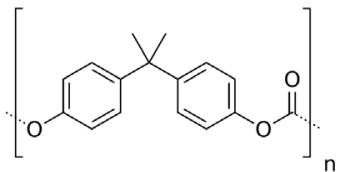

Figure 1. Structural formula of PE, PP and PC.

\section{2. Plasma Treatment}

The DBD plasma treatment was performed in air using DBD reactor Uniplasma 140 (from MSV Systems CZ, s.r.o.). This reactor is equipped with two plane parallel electrodes covered by $1 \mathrm{~mm}$ thick layer of dielectric. The upper electrode $(105 \mathrm{~mm} \times 20 \mathrm{~mm} \times 12 \mathrm{~mm})$ was covered with corundum and the bottom electrode $(120 \mathrm{~mm} \times$ $60 \mathrm{~mm} \times 20 \mathrm{~mm}$ ) with a rubber conveyor belt. The distance between electrodes was $5 \mathrm{~mm}$, AC source voltage was $20 \mathrm{kV}$ at frequency $3 \mathrm{kHz}$ and power $120 \mathrm{~W}$ (PWM modulation was used). The conveyor belt's speed was set to achieve $1 \mathrm{~s}$ long treatment in one pass of the sample under the DBD electrode (i.e. each point of the sample spent $1 \mathrm{~s}$ under the electrode in the plasma discharge). Multiple passes were used to obtain longer treatments. Three treatments were used: $1 \mathrm{~s}, 2 \mathrm{~s}$ and $3 \mathrm{~s}$ long plasma treatment. The treatment was performed in ambient, no other precautions were applied. The relative humidity in the laboratory was between $30-35 \%$.

\section{3. Pull-off Test}

The samples were painted by two types of paint. One of them was water based paint (Balakryl UNI from PPG Deco Czech a.s.) and the other one was solvent based paint (Dupli-Color Aerosol ART from Motip Dupli s.r.o.). The substrates were painted immediately after the treatment and also after 5, 10, 30 and 60 days from the plasma treatment. After the paint dried, the test dolly was glued to the surface by epoxy resin and the pull-off test was performed. Automatic adhesion tester PosiTest AT-A (from company DeFelsko) was used to measure the hydraulic pressure applied by the device to pull the test diameter of coating away from the substrate (dolly with diameter $20 \mathrm{~mm}$ was used). The pull-off test values are averaged values from 6 measurements. The standard deviation of the data lies between $10-25 \%$ of the mean value.

\section{4. Arcotest}

The surface energy can be tested by a commercial test - the Arcotest - that consists of set of inks with defined surface tension $\sigma$. The surface is wetted when it has at least minimal surface energy which is needed to achieve wet- ting of the surface by the ink of given surface tension. It is possible to use inks with $1 \mathrm{mN} / \mathrm{m}$ resolution, however enormous number of samples would be needed. Therefore it was decided to use 3 of the inks in this study. These 3 inks have surface tensions 38,44 and $56 \mathrm{mN} / \mathrm{m}$. The surface energy of the surface is usually considered to be good enough when the surface is wetted by the ink with $\sigma=38 \mathrm{mN} / \mathrm{m}$ or higher. ${ }^{12}$ The adhesion of the paints on such surface is then sufficient.

\section{5. Water Contact Angle Measurements}

The portable instrument See System from AdveX instruments was used for contact angle measurement by static sessile droplet method. The middle part of the sample was used (approx. $1 \mathrm{~cm}$ wide stripe was cut out), $5 \mu \mathrm{L}$ of distilled water was dropped on the sample surface and the contact angle was measured. The measurement was repeated 5 times and mean value was then recorded.

\section{6. XPS Measurements}

The XPS technique was used to reveal the surface chemistry of the samples and for the polar groups detection as these functionalities influence the surface energy as described in literature. ${ }^{13,14}$ Small piece $1 \mathrm{~cm} \mathrm{x} 1 \mathrm{~cm}$ was cut from the middle of the sample and loaded to the XPS chamber. The spectra were recorded using hemispherical analyser Phoibos 100 from Specs operated in FAT mode. Non-monochromatized X-ray beam of $\mathrm{Al}$ anode at $200 \mathrm{~W}$ with $\mathrm{Al} \mathrm{Ka}$ photon energy $1486.6 \mathrm{eV}$ was used. The survey spectra for binding energies from $1300 \mathrm{eV}$ to $0 \mathrm{eV}$ were recorded with pass energy $40 \mathrm{eV}$ with energy step $0.5 \mathrm{eV}$ and dwell time $0.1 \mathrm{~s}$. For C1s and O1s peaks, high resolution spectra were recorded with pass energy equal to $10 \mathrm{eV}$, energy step $0.05 \mathrm{eV}$ and the scan was repeated 10 times. The XPS is not equipped with electron gun for charge compensation, so the spectra were referenced to the peak of aliphatic C-H bonds at $285 \mathrm{eV}$. Quantification was done from high resolution spectra using relative sensitivity factors $\mathrm{RSF}_{\mathrm{C} 1 \mathrm{~s}}=1$ and $\mathrm{RSF}_{\mathrm{O} 1 \mathrm{~s}}=2.93$. Software CasaXPS was used for the spectra processing.

\section{7. AFM Measurements}

The wettability (and adhesion) of the surfaces is influenced by the chemical changes and also by the surface roughness. Therefore, AFM measurements were performed. The NT-MDT Ntegra Aura was used. The cantilevers used for analysis were HA_FM Etalon cantilevers. These AFM tips have longer and shorter cantilever - the shorter one $(183 \mu \mathrm{m})$ in semi-contact mode was used for all AFM images. Images of several sizes were taken $50 \mu \mathrm{m}, 30 \mu \mathrm{m}, 10 \mu \mathrm{m}$ and $5 \mu \mathrm{m}$. Each scan had 256 lines. The NT-MDT software was used for flattening the images (fit lines function was used), for noise filtering and for the 
roughness evaluation. Values of average roughness (Sa) and root mean square roughness $(\mathrm{Sq})$ were recorded.

The problems with charging of the PP and PC samples caused unwanted artefacts in some of the images. This was solved by using filtering of the images. Low pass $3 \times 3$ filter was used in case of PP scans and FFT filtering was needed in case of PC samples. PE scans remained unfiltered.


\section{Results and Discussion}

\section{1. Pull-off Tests}

The adhesion is here expressed in terms of hydraulic pressure (pull-off pressure) needed to pull the test dolly from the sample. Better paint adhesion then results in higher pressure needed to pull off the test dolly. Larger
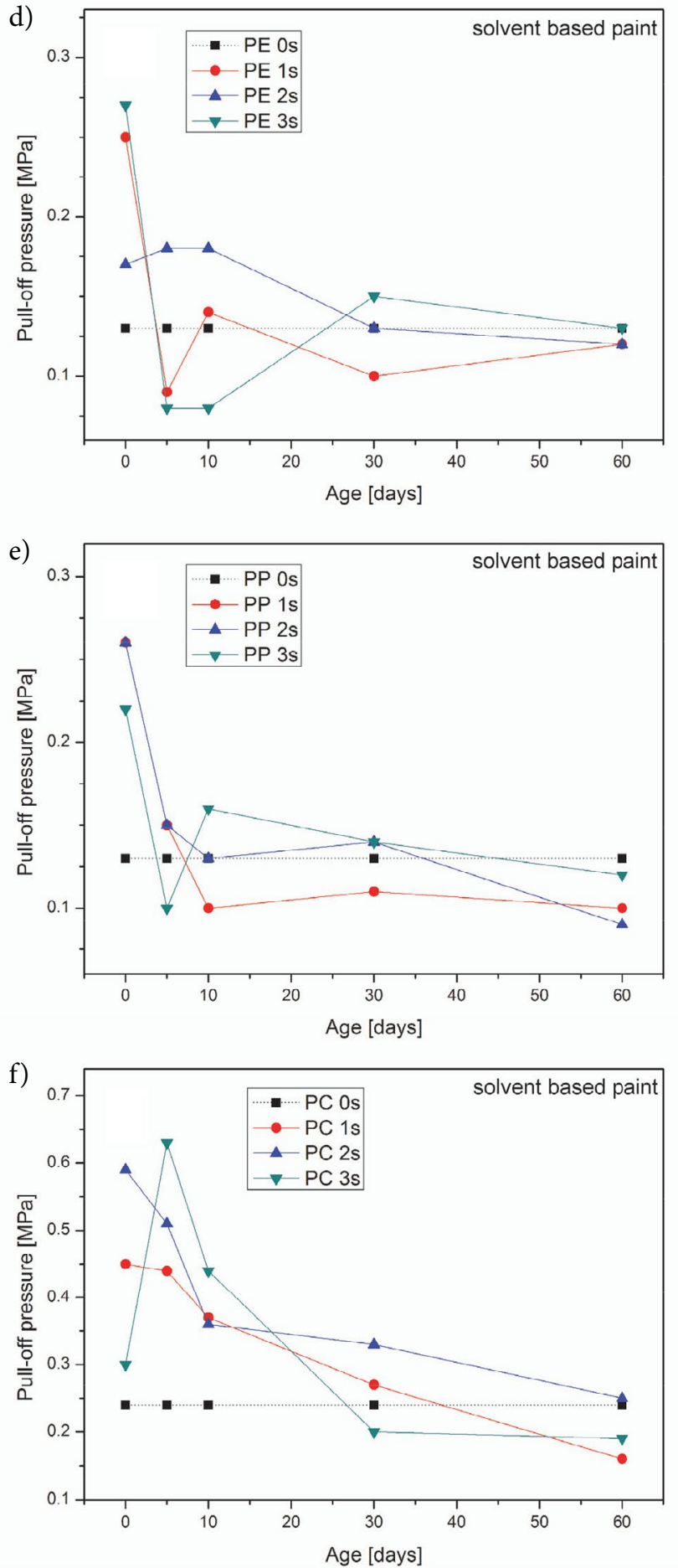

Figure 2. Pull-off test results for water and solvent based paint on the PE, PP and PC substrates. Untreated sample is always labeled " $0 \mathrm{~s}$ " 
standard deviation (10-25\% of the value) is the main reason for higher spread of the data and not clear trends, however, the improvements are undoubted.

The pull-off pressure of the water based paint (Fig.2) increased more than 2 times after the plasma treatment in case of PE. Clear trend is not observable during aging, however, the plasma treated PE seems to keep increased pull-off pressure although its decrease can be seen in the first week of aging. In case of PP, the pull-off pressure increase after the treatment is not so strongly pronounced and also the aging seems to have different character compared to the PE - the increase of the pull-off pressure was found. The reason for this behaviour could be explained by existence of reactive species created on the PP surface followed by the oxidation and incorporation of the oxygen from atmosphere into the polymer surface. This difference between PE and PP samples is also supported by contact angle (Fig.3) and XPS (Fig.4) measurements - the contact angles of PE return back almost to the initial values during the first week of aging while the contact angles on PP return much slowlier. Also the oxygen content given by the XPS decrease back in case of the PE (with the exception of the $3 \mathrm{~s}$ treatment) while in case of the PP the oxygen content stays well above the initial value during the aging. That can be caused by creation of the alkyl and alkoxyl radicals after the plasma treatment as proposed e.g. by Geyter et al. ${ }^{18}$ These radicals can react either with atomic oxygen and ozone in the discharge or with oxygen from atmosphere during the aging. Similar effect was observed, the polar and dispersive fractions of surface energy were measured after atmospheric plasma treatment of PE and PP. ${ }^{19}$ For PE increased polar and dispersive fraction directly after the plasma treatment were found contrary to the PP where significant additional increase of polar fraction also after 8 days after the treatment was observed.

In case of the $\mathrm{PC}$, the pull-off pressure on the water based paint is high even for untreated PC. However, after plasma treatment it is increased further and then slowly decreases to approximately initial values. Considering the fact that untreated $\mathrm{PC}$ already contains $\mathrm{C}-\mathrm{O}$ and $\mathrm{C}=\mathrm{O}$ bonds (and these are believed to be responsible for the good adhesion), this could be expected. The plasma treatment probably changes the two methyl groups (see Fig.1) where hydrogen can be replaced by oxygen containing group and therefore there is still some space for improvement by increasing the amount of oxygen in the polymeric chain.

In case of the solvent based paints both - PE and PP show decrease of the pull-off pressure during first week of aging to almost initial values. The pull-off pressure of untreated PC is low but it is successfully increased by the plasma treatment. It also takes 30 days from the treatment to slowly decrease the values back to the pull-off pressure of untreated PC.

Therefore the adhesion of water based paint is probably governed mainly by the polar groups presence on the surface, while the solvent based paint is not affected that much by them. The effect on the solvent based paint adhesion can be explained if one considers the composition of the solvent based paint. Its safety data sheet gives the information - the paint contains compounds like acetone (up to $50 \%$ ), 2-methoxy-1-methylethyl acetate (up to $10 \%$ ) or butyl acetate (up to 10\%). All these compounds contain polar groups and therefore the adhesion of this paint is influenced by the oxidation of the polymer surface.

\section{2. Arcotest}

The initial surface energy of all untreated samples was low and the surface was not wetted by any of the used inks (surface tensions $\sigma=38,44$ and $56 \mathrm{mN} / \mathrm{m}$ ). This is considered to be insufficient for good adhesion of any paint and therefore the surface of the samples has to be changed. The DBD plasma treated samples show very interesting increase of the surface energy and all of the above mentioned inks wetted the plasma treated surfaces. The durability of the plasma treatment is also important, therefore all analyses were performed on the aged samples too. The Arcotest was done after 1, 5, 10, 30 and 60 days of aging (see Table 1). The most remarkable effect was observed in case of PP, where all treatments led to surface that was wetted by inks with $\sigma=56 \mathrm{mN} / \mathrm{m}$ and remained that high for 2 months. That is in agreement with the pull-off tests where increased pull-off

Table 1. Results of the Arcotest *

\begin{tabular}{|c|c|c|c|c|}
\hline \multirow{2}{*}{\multicolumn{2}{|c|}{ Arcotest }} & \multicolumn{3}{|c|}{$\begin{array}{c}\sigma \text { of inks wetting the sample } \\
{[[\mathrm{mN} / \mathrm{m}]}\end{array}$} \\
\hline & & $\mathbf{P E}$ & $\mathbf{P P}$ & PC \\
\hline \multicolumn{2}{|c|}{ Untreated } & $<38$ & $<38$ & $<38$ \\
\hline \multirow[t]{3}{*}{1 day } & $1 \mathrm{~s}$ & $56 \leq$ & $56 \leq$ & $56 \leq$ \\
\hline & $2 \mathrm{~s}$ & $56 \leq$ & $56 \leq$ & $56 \leq$ \\
\hline & $3 \mathrm{~s}$ & $56 \leq$ & $56 \leq$ & $56 \leq$ \\
\hline \multirow[t]{3}{*}{5 days } & $1 \mathrm{~s}$ & $44<56$ & $56 \leq$ & $56 \leq$ \\
\hline & $2 \mathrm{~s}$ & $56 \leq$ & $56 \leq$ & $56 \leq$ \\
\hline & $3 \mathrm{~s}$ & $56 \leq$ & $56 \leq$ & $56 \leq$ \\
\hline \multirow[t]{3}{*}{10 days } & $1 \mathrm{~s}$ & $38<44$ & $56 \leq$ & $44<56$ \\
\hline & $2 \mathrm{~s}$ & $38<44$ & $56 \leq$ & $44<56$ \\
\hline & $3 \mathrm{~s}$ & $38<44$ & $56 \leq$ & $56 \leq$ \\
\hline \multirow[t]{3}{*}{30 days } & $1 \mathrm{~s}$ & $38<44$ & $56 \leq$ & $56 \leq$ \\
\hline & $2 \mathrm{~s}$ & $38<44$ & $56 \leq$ & $44<56$ \\
\hline & $3 \mathrm{~s}$ & $38<44$ & $56 \leq$ & $44<56$ \\
\hline \multirow[t]{3}{*}{60 days } & $1 \mathrm{~s}$ & $38<44$ & $56 \leq$ & $44<56$ \\
\hline & $2 \mathrm{~s}$ & $38<44$ & $56 \leq$ & $56 \leq$ \\
\hline & $3 \mathrm{~s}$ & $38<44$ & $56 \leq$ & $56 \leq$ \\
\hline
\end{tabular}

${ }^{*}$ Meaning of the inequality sign: $<38$ means the surface energy is lower than energy which should the surface have to be wetted by the ink with $\sigma=38 \mathrm{mN} / \mathrm{m}$.

$56 \leq$ means that the surface energy is equal or higher to the surface energy which should the surface have to be wetted by the ink with $\sigma$ $=56 \mathrm{mN} / \mathrm{m}$.

$38<44$ means that surface energy is between the surface energies that should surface have to be wetted by the inks with $\sigma=38$ and $44 \mathrm{mN} / \mathrm{m}$. This results in wetting by ink with $\sigma=38 \mathrm{mN} / \mathrm{m}$ and partial wetting by ink with $\sigma=44 \mathrm{mN} / \mathrm{m}$. The $44<56$ is similar. 
pressure was detected for water based paint. Very positive effect was obtained also for the PC samples, where slight decrease of the surface energy after approx. 2 weeks is observed, but is still good enough to be wetted by ink with $\sigma=44 \mathrm{mN} / \mathrm{m}$. The biggest changes are seen in case of PE. In the first week from the treatment, the surface energy keeps the high values (ink with $\sigma=56 \mathrm{mN} / \mathrm{m}$ ) but after one week it drops to the $44-56 \mathrm{mN} / \mathrm{m}$ interval and after two weeks of aging drops further to $38-44 \mathrm{mN} / \mathrm{m}$. This behaviour could be ascribed to the hodrophobic recovery described in literature. ${ }^{20-22}$ The functional groups can be rotated along the main chain of the polymer and can be burried into the deeper layers of the polymer. The PE chains are mostly linear and as a consequence the functional groups are easily rotated and burried. The other two polymers have more complex structure and therefore less degrees of freedom, which probably prevents above described mechanism from prevailing. The Arcotest results on PE are in accordance with the pull-off tests and the water contact angle measurements. It is not exactly known to the authors of this article whether the Arcotest is consisting mainly of polar or dispersive components, but from the results of pull-off tests and also the water contact angle measurements it looks like the polar ink is the main component of the testing liquids.

\section{3. Water Contact Angle Measurements}

The water contact angle measurement is simple and easy way to gain some information about the polar component of the surface energy.

The untreated samples have contact angle values close to $100^{\circ}(\mathrm{PE}, \mathrm{PP})$ and $80^{\circ}(\mathrm{PC})$. The lower contact angle in case of $\mathrm{PC}$ can be attributed to oxygen presence on its surface as mentioned earlier. Directly after the plasma treatment the contact angles decrease significantly by approximately $20-30^{\circ}$ (see Fig.3). The trends are similar to those observed for Arcotest and pull-off measurements - the PE recovers almost to the initial values after 1 week of aging, the treatment in case of rest of the samples returns more slowly. The PP contact angles are recovering too, although the surface energy given by the Arcotest remains stable. This is most likely given by low resolution of the Arcotest (only 4 distinguishable values). The longer $3 \mathrm{~s}$ treatment is slightly more stable than $1 \mathrm{~s}$ or $2 \mathrm{~s}$ treatment for all polymers.

\section{4. XPS Measurements}

The XPS measurements confirmed the above testing - initial oxygen content is low in case of PE and PP and therefore the contact angles are high and the pull-off pressures low for both polymers (see Fig. 4). The difference is in the speed of the recovery process. The fastest return to initial O content has the PE, where lowest surface energy was found with aging as well as the water contact angle measurements on PE showed the fastest return to almost initial contact angles. The PP has the best retention of the a)

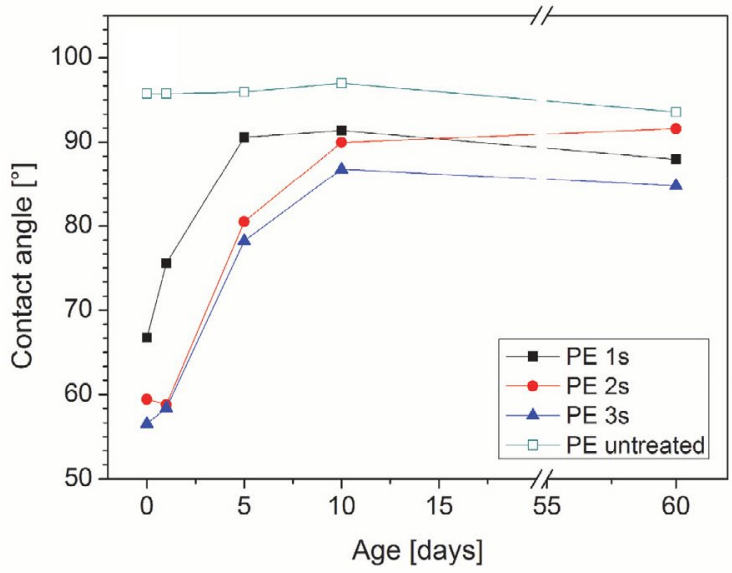

b)

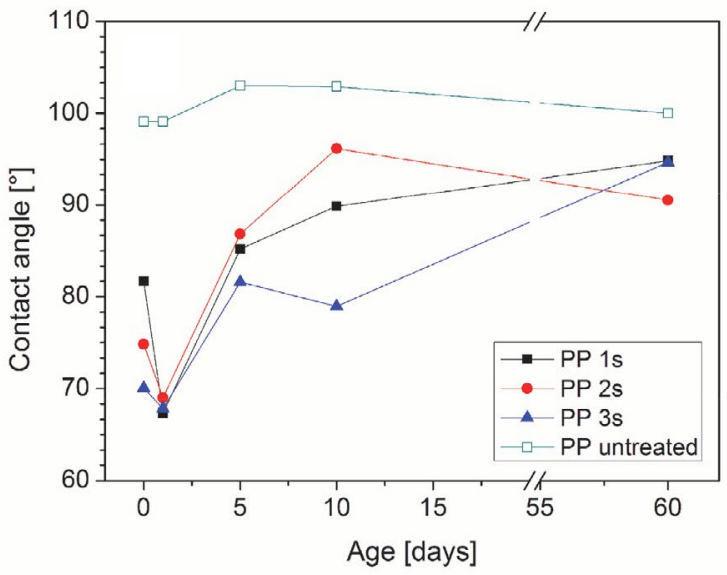

c)

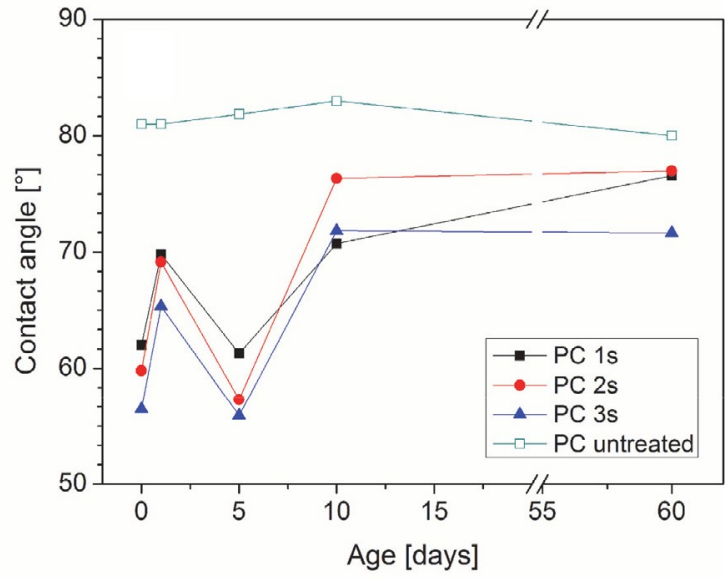

Figure 3. Measurement of contact angle of water on a) PE, b) PP and c) PC substrates after various DBD plasma treatments.

oxygen on the surface from all three studied polymers and therefore the Arcotest measurements show wetting of inks with surface tension above $56 \mathrm{mN} / \mathrm{m}$ after the plasma treatment (as already mentioned the Arcotest seems to be based on polar inks). In case of untreated PC, the oxygen content given by XPS begins at higher values and as a consequence the pull-off pressure (of water based paint) is significantly higher than in case of the PE and PP. After the plasma treatment the oxygen contents is increased which 
in turn results in increased pull-off pressure and lowered contact angle. The oxygen content then returns to the initial values, however the wetting remains significantly increased $(\sigma$ over $44 \mathrm{mN} / \mathrm{m})$ after aging. It is possible that some of the polar groups created by the plasma remained on the PC surface, but the XPS is not sensitive enough to distinguish those different conditions of the surface.

a)



b)

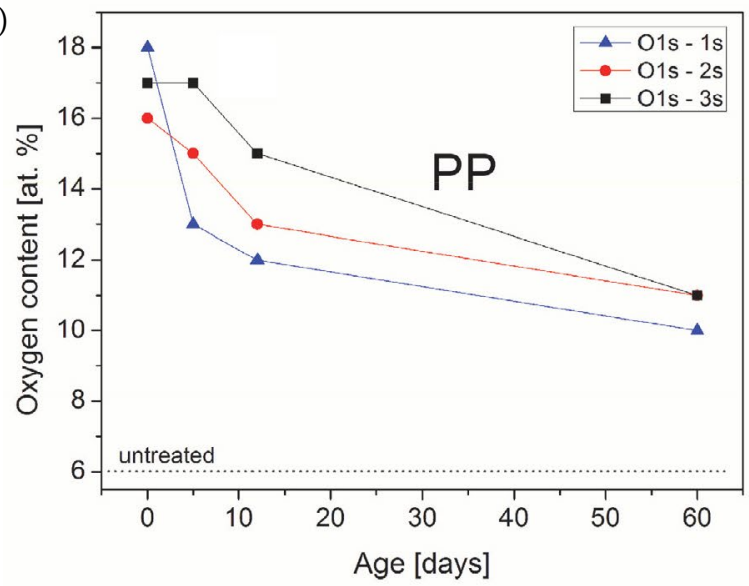

c)

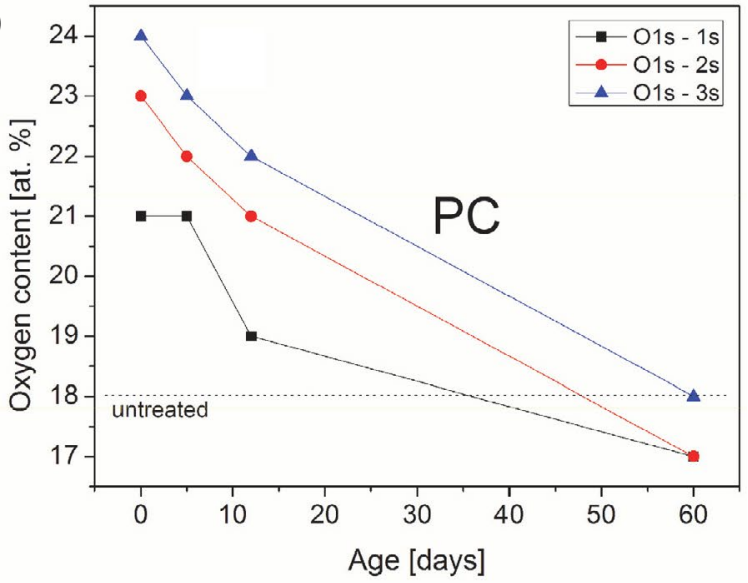

Figure 4. Oxygen contents on plasma treated a) PE, b) PP and c) PC surfaces in atomic \% given by XPS. The dashed lines show the oxygen content of untreated polymers.

\section{5. AFM Results}

Images of 4 different scan sizes were taken for untreated samples and $3 \mathrm{~s}$ long treated ones. Scans with square sides $50 \mu \mathrm{m}, 30 \mu \mathrm{m}, 10 \mu \mathrm{m}$ and $5 \mu \mathrm{m}$ were recorded. The roughness differs for all scan sizes for various reasons - the true size of one image point (pixel) differs, the irregular


Figure 5. Root mean square roughness calculated from AFM images of untreated (filled squares) and plasma treated samples (circles). $10 \mu \mathrm{m}$ scan size is optimal. 
Table 2. Roughness values and their standard deviations calculated from AFM scans.

\begin{tabular}{lccccrrrr}
\hline & \multicolumn{2}{c}{$\mathbf{5 0} \boldsymbol{\mu \mathbf { m }}$} & \multicolumn{2}{c}{$\mathbf{3 0} \boldsymbol{\mu m}$} & \multicolumn{2}{c}{$\mathbf{1 0} \boldsymbol{\mu m}$} & \multicolumn{2}{c}{$\mathbf{5 m}$} \\
& $\mathbf{S}_{\mathbf{a}}[\mathbf{n m}]$ & $\mathbf{S}_{\mathbf{q}}[\mathbf{n m}]$ & $\mathbf{S}_{\mathbf{a}}[\mathbf{n m}]$ & $\mathbf{S}_{\mathbf{q}}[\mathbf{n m}]$ & $\mathbf{S}_{\mathbf{a}}[\mathbf{n m}]$ & $\mathbf{S}_{\mathbf{q}}[\mathbf{n m}]$ & $\mathbf{S}_{\mathbf{a}}[\mathbf{n m}]$ & $\mathbf{S}_{\mathbf{q}}[\mathbf{n m}]$ \\
\hline PE & $25.3 \pm 6.3$ & $41.3 \pm 15.9$ & $12.3 \pm 1.4$ & $16.0 \pm 1.9$ & $7.2 \pm 0.6$ & $9.1 \pm 0.7$ & $5.6 \pm 0.6$ & $6.9 \pm 0.8$ \\
PE 3s & $15.3 \pm 7.0$ & $22.4 \pm 15.8$ & $13.1 \pm 1.2$ & $17.0 \pm 1.6$ & $10.1 \pm 2.1$ & $13.1 \pm 2.8$ & $7.6 \pm 2.0$ & $10.1 \pm 2.4$ \\
PP & $18.0 \pm 3.0$ & $23.0 \pm 3.1$ & $12.8 \pm 1.3$ & $16.5 \pm 1.6$ & $6.9 \pm 0.6$ & $8.9 \pm 0.7$ & $4.9 \pm 0.5$ & $6.5 \pm 0.7$ \\
PP 3s & $26.6 \pm 2.5$ & $33.8 \pm 4.5$ & $14.6 \pm 1.4$ & $18.2 \pm 1.5$ & $6.5 \pm 0.5$ & $8.5 \pm 0.6$ & $5.7 \pm 0.4$ & $7.4 \pm 0.5$ \\
PC & $20.3 \pm 3.0$ & $27.4 \pm 2.7$ & $14.7 \pm 2.8$ & $19.5 \pm 3.5$ & $7.6 \pm 1.2$ & $10.1 \pm 1.4$ & $5.0 \pm 1.7$ & $6.4 \pm 1.8$ \\
PC 3s & $30.4 \pm 13.3$ & $43.0 \pm 19.3$ & $23.5 \pm 8.8$ & $32.5 \pm 12.9$ & $24.2 \pm 12.0$ & $28.9 \pm 13.3$ & $7.8 \pm 1.8$ & $10.0 \pm 2.1$ \\
\hline
\end{tabular}

surface features can be avoided in case of smaller scan sizes. Roughness values obtained are given in Table 2 together with their standard deviations. Each number (number pair respectively $-S_{a}$ and $S_{q}$ are computed from the same image) is calculated as mean value from 3 images. The scan size $10 \mu \mathrm{m}$ can be considered as optimal. Unwanted features are mostly out of the scan area while the scan is big enough to be representative sample of the surface.

In all cases, small increase of the roughness was observed. Although the difference is not very big compared e.g. to T. Shao or M. Gao, the roughness increase can support the chemical changes induced by the plasma treatment. ${ }^{17,23}$ The roughness difference in case of the PC scan (size $10 \mu \mathrm{m}$ ) is quite large, but the data obtained for plasma treated PC were quite noisy - lots of horizontal streaks had to be removed. The fourier transform filtering helped, but still the quality of the scans on PC was lower and deviation of the values is large. The root mean square roughness can be seen in Figure 5. The average roughness has similar tendency

\section{Conclusions}

Three polymers (PE, PP, PC) were treated by DBD plasma discharge in air. In all cases, improvement of desired properties was achieved, i.e. pull-off test showed increased adhesion of water based and solvent based paints. The solvent based paint adhesion was probably improved due to presence of oxygen containing compounds in the paint. The results of other techniques are in good agreement with the pull-off tests - oxygen content (XPS) increases after plasma treatment, contact angle decreases and surface energy (Arcotest) is increased and the polymer surface is wetted by testing liquid with $\sigma=56 \mathrm{mN} / \mathrm{m}$. The AFM measurements of roughness confirmed, that chemical changes were supported by small increase of roughness. The aging affects all of the polymers and hydrophobic recovery probably takes place. The PE is the polymer most prone to the aging in this case. Most stable behaviour was observed in case of PP, which may be given by its structure where the polymer chains have limited degrees of freedom compared to PE. Adhesion of the water based paint seems to be controlled by the polar groups while the adhesion of the solvent based paint is not influenced by them.

\section{Acknowledgements}

The publication is a result of the project Development of the UniCRE Centre (project code LO1606) which was financially supported by the Ministry of Education, Youth and Sports of the Czech Republic under the National Programme for Sustainability I. The publication is a result of the project „Development of textile products from non-combustible and recyclable materials", registration number CZ.01.1.02/0.0/0.0/16_084/0010282, were obtained through the financial support of the Ministry of Industry and Trade in the framework of the targeted support of the "Application III", the Operational Programme Enterprise and Innovations for Competitiveness. This research was supported by grant within student grant competition at University of J.E.Purkyně in Ustí nad Labem, project No.: UJEP-SGS-2018-53-006-3.

\section{References}

1. D. M. Brews, D. Briggs, Polym. 1981, 22, 7-16. DOI:10.1016/0032-3861(81)90068-9

2. Add R. A. Wolf in: Plastic surface modification: surface treatment, decoration, and adhesion Hanser Publications, München, Germany, 2010.

3. C. M. Chan, T. M. Ko, H. Hiraoka, Surf. Sci. Rep. 1996, 24, 1-54. DOI:10.1016/0167-5729(96)80003-3

4. M. R. Wertheimer, A. C. Fozza, A. Holländer, Nucl. Instrum. Methods Phys. Res. B 1999, 151, 65-75.

DOI:10.1016/S0168-583X(99)00073-7

5. P. Favia, R. d'Agostino, Surf. Coat. Technol. 1998, 98, 11021106. DOI:10.1016/S0257-8972(97)00285-5

6. T. Shen, Y. Liu, Y. Zhu, D.-Q. Yang, E. Sacher, Appl. Surf. Sci. 2017, 411, 411-418. DOI:10.1016/j.apsusc.2017.03.149

7. F. Arefi-Khonsari, J. Kurdi, M. Tatoulian, J. Amouroux, Surf. Coat. Technol. 2001, 142, 437-448.

DOI:10.1016/S0257-8972(01)01240-3

8. E. M. Liston, L. Martinu, M. R. Wertheimer, J. Adhes. Sci. Technol. 1993, 7, 1091-1127. DOI:10.1163/156856193X00600 
9. M. H. Blees, G. B. Winkelman, A. R. Balkende, J. M. J. den Toonder, Thin Solid Films 2000, 359, 1-13. DOI:10.1016/S0040-6090(99)00729-4

10. M. A. Naveed, A. Qayyum, S. Ali, M. Zakaullah, Phys. Letters A 2006, 359, 499-503. DOI:10.1016/j.physleta.2006.07.002

11. F. J. Andrade, W.C. Wetzel, G. C.-Y. Chan, G. Gamez, S. J. Ray, G. M. Hieftje, J. Anal. At. Spectrom. 2006, 21, 1175-1184. DOI:10.1039/b607544d

12. https://arcotest.info/wp-content/uploads/2018/06/arcotestenglish.pdf (accessed: April 4, 2019)

13. J. Behnish, A. Holländer, H. Zimmermann, Surf. Coat. Technol. 1993, 59, 356-358. DOI:10.1016/0257-8972(93)90112-2

14. S. H. Park, S. D. Kim, Colloids Surf. A Physicochem. Eng. Asp. 1998, 133, 33-39.

15. J. P Píchal, L. Aubrecht, J. Hladík, P. Špatenka, Czech. J. Phys. 2006, 56, B1290-B1294. DOI:10.1007/s10582-006-0364-3

16. Ch. Liu, N. Cui, N. M. D. Brown, B. J. Meenan, Surf. Coat. Technol. 2004, 185, 311-320.

DOI:10.1016/j.surfcoat.2004.01.024
17. T. Shao, C. Zhang, K. Long, D. Zhang, J. Wang, P. Yan, Y. Zhou, Appl. Surf. Sci. 2010, 256, 3888-3894.

DOI:10.1016/j.apsusc.2010.01.045

18. N. De Geyter, R. Morent, C. Leys, L. Gengembre. E. Payen, Surf. Coat. Technol. 2007, 201, 7066-7075.

DOI:10.1016/j.surfcoat.2007.01.008

19. N. Encias, B. Díaz-Benito, J. Abenojar, M. A. Martínez, Surf. Coat. Technol. 2010, 205, 396-402.

DOI:10.1016/j.surfcoat.2010.06.069

20. T. R. Gengenbach, Z. R. Vasic, R. C. Chatelier, H. J. Griesser, Plasmas Polym. 1996, 1, 207-228. DOI:10.1007/BF02532817

21. M. Motrazavi, M. Nosovsky, Appl. Surf. Sci. 2012, 258, 68766883. DOI:10.1016/j.apsusc.2012.03.122

22. D. Hegemann, E. Lorusso, M.-I. Butron-Garcia, N. E. Blanchard, P. Rupper, P. Favia, M. Heuberger, M. Vandenbossche, Langmuir 2016, 32, 651-654.

DOI:10.1021/acs.langmuir.5b03913

23. M. Gao, L. Sun, Y. Guo, J. Shi, J. Zhang., Chem. Phys. Lett. 2017, 689, 179-184. DOI:10.1016/j.cplett.2017.10.009

\section{Povzetek}

Substrate iz polietilena (PE), polipropilena (PP) in polikarbonata (PC) smo obdelali z dielektrično barierno razelektritveno plazmo (DBD) na zraku (1 s, $2 \mathrm{~s}, 3 \mathrm{~s}$ ). Oprijem dveh vrst barv (na vodni osnovi in na osnovi topil) smo preučevali s preizkusom z odtrganjem (pull-off test). Za pridobivanje informacij o površini vzorcev smo uporabili tudi druge metode. $\mathrm{Z}$ meritvami kontaktnega kota vode, Arcotestom (komercialni test $\mathrm{z}$ uporabo tekočin $\mathrm{z}$ določeno površinsko napetostjo) in rentgensko fotoelektronsko spektroskopijo (XPS) smo pridobili podatke o kemijski sestavi površine vzorca. Preizkus z odtrganjem je potrdil povečan oprijem obeh vrst barv, kar je povezano z vsebnostjo kisika, ki smo jo potrdili z rentgensko fotoelektronsko spektroskopijo (XPS). Tudi po daljšem časovne obdobju (60 dni) so vzorci ohranili svoje izboljšane lastnosti. 